\title{
Tympanoplasty for Wet and Dry Perforation: A Prospective Comparative Study
}

https://doi.org/10.47210/bjohns.2020.v28i3.290

Amit Bikram Maiti, ${ }^{1}$ Rupam Sinha ${ }^{2}$

$\underline{\text { Introduction }}$

\section{ABSTRACT}

Two types of surgical procedures are performed for the treatment of Chronic otitis media (COM) mucosal disease, namely myringoplasty and tympanoplasty. In the present study, an objective, comparative evaluation between the outcomes of tympanoplasty, performed in the 'wet ear' and the 'dry (non-discharging) ear' has been undertaken.

Materials and Methods

A prospective study was conducted in a peripheral referral institute over a period of 37 months wherein a total of 105 patients with tympanic membrane perforation were selected, amongst which 56 patients had moist ear and 49 patients had dry ear. All of the patients underwent tympanoplasty by underlay technique. Final results were analyzed 12 months post operatively.

$\underline{\text { Results }}$

In the wet ear group amongst 56 patients, 51 patients had successful graft uptake (91.07\%). In dry ear group, among 49 patients, successful graft uptake was seen in 44 cases $(89.79 \%)$. In the wet ear group 50 out of 56 patients had hearing improvement (89.28\%). In dry ear group 44 out of 49 patients had hearing improvement (89.79\%). Statistically significant results were obtained postoperatively in each group; however, inter group analyses showed no statistical significance.

\section{Conclusion}

Success rate of tympanoplasty does not depend upon the wet or dry state of middle ear at the time of surgery.

$\underline{\text { Keywords }}$

Tympanoplasty; Myringoplasty; Otitis Media

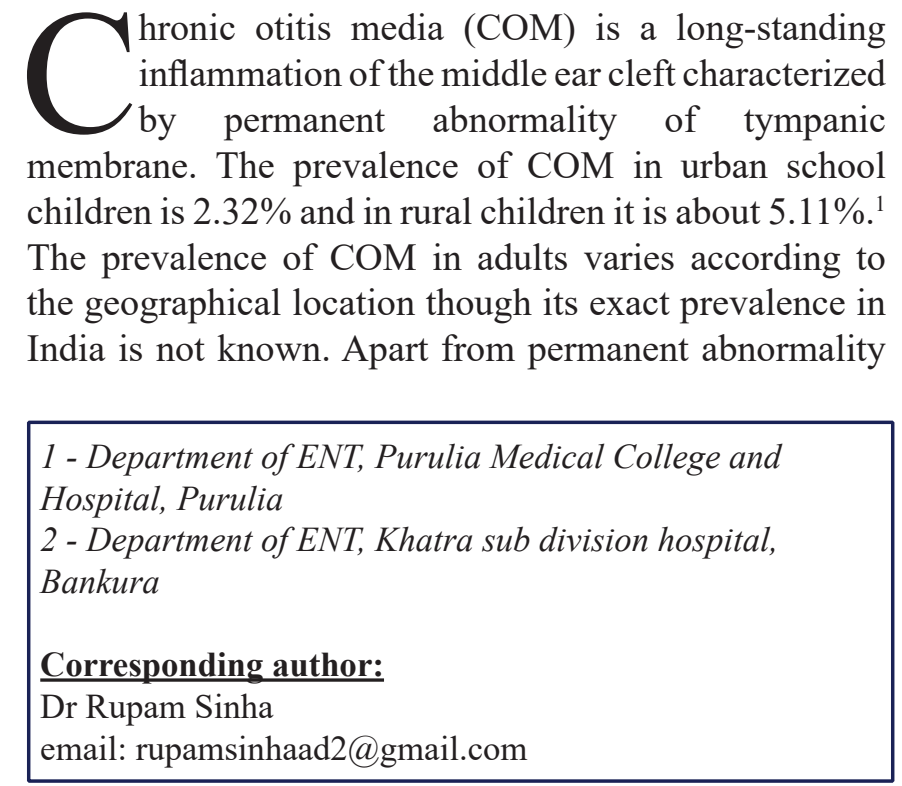

of tympanic membrane, COM is associated with aural polyp and resorptive osteitis of ossicular chain. ${ }^{2}$ Clinically COM is divided into mucosal and squamous varieties. In cases of mucosal disease tympanoplasty plays an important role in preventing discharge from ear, hearing improvement and eradication of disease from middle ear cleft. ${ }^{3}$

Two types of surgical procedures are performed for the treatment of mucosal disease, namely myringoplasty and tympanoplasty. Myringoplasty is limited to simple grafting of tympanic membrane perforation. In tympanoplasty ossicular chain inspection/reconstruction is performed along with grafting of tympanic membrane. Success rate of tympanoplasty depends on various factors like position of perforation, type of perforation (small central, subtotal, total perforation), eustachian 
tube function, pre-operative dry or wet status of middle ear, surgical techniques etc. Other factors which also influence the outcome of tympanoplasty include chronic sinusitis, deviated nasal septum, adenoid enlargement and discharge from other ear. From the clinical experience of the authors it has been seen that a significantly large number of patients who have been advised tympanoplasty do not have a dry ear on the day of surgery. The dilemma continues whether to operate now or to defer the surgery till the ear becomes completely dry. On an average, adults catch a cold 4 to 6 times a year, while children get them 6 to 8 times. ${ }^{4}$ With each episode of common cold chances of conversion from inactive to active stage of mucosal COM increase.

The average waiting times for various elective surgeries in OECD (Organisation for Economic Cooperation and Development) countries varies from 30 days to more than 7 months whereas for National Health Service in the United Kingdom it is more than 18 weeks for elective cases. ${ }^{5,6}$ Though no such official data is available for our country, significantly high waiting times in government hospitals results in increased stress, prolonged functional impairment along with increased chances of conversion to active disease resulting in further delay in treatment. In the present study, an objective, comparative evaluation between the outcomes of tympanoplasty, performed in the "wet ear' and the 'dry (non- discharging) ear' to compare the results of tympanoplasty in dry and wet perforation in terms of graft intake and hearing improvement.

\section{Materials and Methods}

This study was conducted in the Department of Otorhinolaryngology and Head - Neck Surgery, of a peripheral referral institute in West Bengal, India over a period of 37 months (April 2015 to April 2018). Patients of COM aged between 10-60 years of age with central perforation and purely conductive hearing loss were selected for this study. Patients with squamous disease or sensorineural hearing loss and those unwilling to participate in the study were excluded. Individuals with pus or smelly discharge were initially treated with a course of antibiotics based on culture sensitivity reports along with topical ear drops and antihistamines. Patients with active purulent discharge had their surgeries deferred till it became completely dry or the discharge was mucoid and devoid of any smell.

Criteria for dry ear: The ear should be free from discharge for the last 6 months; middle ear mucosa and remnant of tympanic membrane will be of normal colour, not congested.

Criteria for wet ear: Congestion in remnant of tympanic membrane; congested middle ear mucosa; presence of mucoid discharge but no frank pus in the middle ear and/or polypoidal change in middle ear mucosa.

Institutional ethics clearance was obtained before conducting this study. Written informed consent was taken either from the study subjects or their next of kin. Study proforma consisting of name, age, sex, type of perforation, wet or dry middle ear status, pre and post-operative hearing status (measured in decibel), graft uptake and re-perforation was constructed. All cases underwent thorough clinical evaluation and those individuals found to be having known factors (deviated nasal septum, chronic sinusitis etc) which influence the outcome of tympanoplasty were initially treated for the same before definitive surgery was undertaken. Examination under microscope was done in all cases to evaluate the status of the ear pre- operatively including the colour of the middle ear mucosa. Each individual was advised a skiagram of the mastoids (lateral oblique view). Pure tone audiometry (using Bracketing method) and impedance audiometry (to assess Eustachian tube function) was performed (by the same audiologist) in a sound proof audiometry booth using the same audiometer both pre and post operatively. Routine preoperative investigations were performed.

The surgical procedure was performed by the first author in all of the cases in a single institution. The surgery was carried out under local anesthesia in most of the cases; general anaesthesia being used for those who could not co-operate under local anaesthesia. Endaural or post aural incision was made; margins of perforation were made raw; undersurface of tympanic membrane remnant was scraped to remove any epithelium; tympanosclerotic patch over the remnant of tympanic membrane, if any, was removed; tympanomeatal flap 
Table I: Distribution of study population based on sex

\begin{tabular}{|c|c|c|c|}
\hline TYPE OF PERFORATION & FEMALE & MALE & GRAND TOTAL \\
\hline Dry & $26(46 \%)$ & $23(47 \%)$ & $49(47 \%)$ \\
\hline Wet & $30(54 \%)$ & $26(53 \%)$ & $56(53 \%)$ \\
\hline Grand Total & 56 & 49 & 105 \\
\hline
\end{tabular}

was elevated; any polypoidal or granulation tissue found was removed from the middle ear; type 1 tympanoplasty was performed using temporalis fascia graft by underlay technique. Details of intra operative findings including status of ossicular chain, chorda tympani nerve and any facial nerve injury were recorded. Follow up was done at the end of 1st, 3rd, 6th and 12th month. Graft uptake or rejection at the end of 12 post-operative months along with post operative audiogram were taken for calculating the results. The data was analyzed using MicrosoftExcel software; statistical tests like paired and unpaired $\mathrm{T}$ tests were performed using the same software.

\section{Results}

This study was conducted on a total 105 patients, with 49 males (47\%) and 56 females (53\%). These patients were divided into two groups: dry ear and wet ear. Total number of patients in the dry ear group was $49(47 \%)$ and in wet ear group was 56 (53\%). (Table I) Maximum number of individuals belonged to 21-30 years age group followed by 31-40 years age group. Least number of patients belonged to the age group of 51-60 years.

Pre operative air conduction hearing thresholds are shown in Table II. The majority of patients both in dry and wet perforation group had hearing loss in the $41-50$ $\mathrm{db}$ HL range followed by $31-40 \mathrm{db} \mathrm{HL}$ range.

In the wet ear group, out of 56 patients, successful graft uptake was seen in 51 cases (91.07\%). In the dry ear group, out of 49 patients successful graft uptake was seen in 44 cases $(89.79 \%)$. But this result is not statistically significant $(\mathrm{p}$ value $=0.9999$. Fischer exact test).

The mean hearing gain in the wet ear group was $15.9175 \mathrm{db}$ which is statistically significant $(\mathrm{p}<0.001)$ and that in the dry ear group was $16.9057 \mathrm{db}$ which is also statistically significant $(p<0.001)$. However on comparing the hearing gain between the wet and dry

Table II: Pre operative hearing status

\begin{tabular}{|c|c|c|c|c|}
\hline \multirow{2}{*}{$\begin{array}{c}\text { PRE-OPERATIVE A-C } \\
\text { THRESHOLD }\end{array}$} & \multicolumn{2}{|c|}{ DRY EAR } & \multicolumn{2}{c|}{ WET - EAR } \\
\cline { 2 - 5 } & CASES & PERCENTAGE & CASES & PERCENTAGE \\
\hline $11-20 \mathrm{db}$ HL & 0 & 0 & 0 & 0 \\
\hline $21-30 \mathrm{db}$ HL & 0 & 0 & 0 & 0 \\
\hline $31-40 \mathrm{db}$ HL & 21 & $42.85 \%$ & 24 & $42.85 \%$ \\
\hline $41-50 \mathrm{db}$ HL & 25 & $51.02 \%$ & 25 & $44.64 \%$ \\
\hline $51-60 \mathrm{db}$ HL & 2 & $4.08 \%$ & 5 & $8.93 \%$ \\
\hline
\end{tabular}


Table III: Comparison of pre and post operative hearing status (according to AC threshold)

\begin{tabular}{|c|c|c|c|c|}
\hline & & AGE (YEARS) & $\begin{array}{c}\text { PRE-OP HEARING } \\
\text { (DB HL) }\end{array}$ & $\begin{array}{c}\text { POST-OP } \\
\text { HEARING (DB HL) }\end{array}$ \\
\hline \multirow{4}{*}{ Dry Ear } & Mean & 27.47 & 41.73 & 24.83 \\
\cline { 2 - 5 } & Minimum & 11 & 30 & 18.33 \\
\cline { 2 - 5 } & Maximum & 55 & 51.66 & 51.66 \\
\cline { 2 - 5 } & Median & 26 & 43.33 & 21.66 \\
\cline { 2 - 5 } & Mean & 28.2 & 41.09 & 18.33 \\
\cline { 2 - 5 } & Minimum & 15 & 30 & 51.66 \\
\cline { 2 - 5 } & Maximum & 56 & 51.66 & 21.66 \\
\hline
\end{tabular}

ear groups using unpaired ' $\mathrm{t}$ ' test statistically significant difference was not seen $(\mathrm{p}=0.249741)$.

In the wet ear group 6 patients had no hearing improvement. Among them, 1 patient had ossicular fixation detected at the time of operation, 2 patients had dehiscence of graft in protympanic area at 1 month follow up, 2 patients had perforation in newly formed tympanic membrane at 3 month visit following an upper respiratory tract infection, 1 patient had re-perforation of newly formed tympanic membrane without any definite etiology. In dry ear group, 5 patients had no hearing improvement, 1 patient had ossicular fixation detected at the time of surgery, 2 patients had medialization of graft at the end of 3 month follow up and 2 patients had perforation in newly formed tympanic membrane following upper respiratory tract infection at 6 months follow up.

\section{Discussion}

Chronic otitis media is divided into two types, mucosal variety and squamous variety. Mucosal variety is more common and is characterized by perforation in pars tensa of tympanic membrane. This perforation results from middle ear infection, trauma or iatrogenic causes. Spontaneous healing rate of traumatic perforation after 3 months follow up is $82.3 \% .^{7}$ Spontaneous closure of tympanic membrane is uncommon in case of COM and surgical treatment is necessary to close the perforation. The aim of surgery is closure of tympanic membrane perforation to prevent recurrent discharge from ear and improvement of hearing.

Different graft materials are used for closure of tympanic membrane perforation. At the beginning of tympanoplasty surgery, Wullstein and Zollner used split thickness skin as graft material but subsequently it was rejected owing to its numerous disadvantages. ${ }^{8}$ From 1980 onwards most surgeons started using mesoderm-originated graft material such as temporalis fascia, perichondrium, vein graft, loose areolar tissue which exclude chances of iatrogenic cholesteatoma. ${ }^{9}$ Many factors may affect the outcome of surgery like type of perforation, dry or wet perforation, condition of contralateral ear, type of graft materials, expertise of surgeon etc. In our study we are more concerned with effect of wet and dry perforation on final outcome of tympanoplasty. We selected a total of 105 patients over a period of 37 months. Our study had a male: female ratio of 1:1.12 which is comparable with the study of Yi - Chaio Lin et al. where male: female is $1: 1.21 .{ }^{10} \mathrm{In}$ our study $89.5 \%$ of patients were in the age group of $11-40$ years with a mean age of 27.86 years, median age 27.00 years with standard deviation (SD) of 9.131. Our study is comparable with the study of Prakash Mishra et al., 
Table IV: Comparative results of graft uptake in the various studies

\begin{tabular}{|c|c|c|}
\hline STUDY & WET EAR GROUP & DRY EAR GROUP \\
\hline Our study & $91.07 \%$ & $89.79 \%$ \\
\hline Nagle SK et al., 2009 & $74 \%$ & $88 \%$ \\
\hline Hosny S et al, 2014 & $\mathbf{8 7 \%}$ & $90.40 \%$ \\
\hline Gamra OB et al., 2016 & $\mathbf{8 8 \%}$ & $\mathbf{8 7 . 5 0 \%}$ \\
\hline Chandrasekhar Y et al., 2017 & $\mathbf{8 6 . 7 0 \%}$ & $90 \%$ \\
\hline Pothala et al., 2018 & $\mathbf{9 8 . 5 0 \%}$ & $98.50 \%$ \\
\hline
\end{tabular}

where $89 \%$ of cases were in the age group of $11-40$ years. $^{11}$

In our study graft uptake rate in dry ear was $89.79 \%$ and that in wet ear was $91.07 \%$. In their study, Nagle et al. found a graft uptake rate of $88 \%$ in the dry ear group and $74 \%$ in the wet ear group. ${ }^{12}$ Chandrasekhar et al. demonstrated graft uptake rates of $90 \%$ and $86.7 \%$ for dry ear and wet ear respectively. ${ }^{13}$ No statistical difference was found ( $p$ value 0.688 ). In their study, Gamra et al. showed that graft integration rate was $87.5 \%$ in dry ear group and $88 \%$ in wet ear group, without any statistically significant difference $(p=0.9) .{ }^{14}$ Sivasankari showed graft uptake rate was $86.6 \%{ }^{15}$ Pothala et al. exhibited a higher percentage of graft uptake for both dry and wet ear, 98.5\% in each case. ${ }^{16}$ Hosny showed graft uptake rates of $90.4 \%$ in dry ear and $87 \%$ for wet ear. ${ }^{17}$ Sheehy found that successful closure of tympanic membrane is over $97 \%{ }^{18}$ Andersen in his study showed graft uptake rate of $93 \%$ at 2 to 6 months and $86.6 \%$ at more than 12 months. ${ }^{19}$ In our study graft uptake is slightly better in wet ear group compared to dry ear group. (Table IV)
This can be explained by density of inflammatory cells and blood vessels in the remnant of tympanic membrane of wet ears in contrast to the marginalized blood vessels in dry and atrophic membrane of dry perforation.

There are many methods for assessing hearing gain after COM surgery like social hearing method, air conduction threshold estimation, hearing gain method, mean A-B gap method, but none are universally accepted. ${ }^{20}$ In our study we used the air conduction threshold for comparing hearing results.

In our study, in the wet ear group, out of 56 patients, 50 patients $(89.28 \%)$ had hearing improvement. In the dry ear group 44 out of 49 patients had hearing gain $(89.79 \%)$. This result is not statistically significant ( $p$ value 0.9999 , Fisher exact test). Out study corroborates with the study of Kumar et al. where successful hearing improvement was seen in $93.3 \%$ of cases with mean post-operative air-bone gap in final follow up being $13.67+5.56 \mathrm{db} .{ }^{21}$ Pothala et al. demonstrated hearing improvement in $87.14 \%$ of dry ear cases and $77.14 \%$ cases of wet ear. ${ }^{16}$ Study by Hosny et al. in 2014 showed

Table V: Comparative results of hearing improvement in the various studies

\begin{tabular}{|c|c|c|}
\hline STUDY & WET EAR GROUP & DRY EAR GROUP \\
\hline Our study & $\mathbf{8 9 . 2 8 \%}$ & $\mathbf{8 9 . 7 9 \%}$ \\
\hline Pothala et al., 2018 & $\mathbf{7 7 . 1 4 \%}$ & $\mathbf{8 7 . 1 4 \%}$ \\
\hline Hosny et al., 2014 & $\mathbf{9 1 . 3 0 \%}$ & $\mathbf{9 2 . 3 0 \%}$ \\
\hline
\end{tabular}


hearing improvement was $91.3 \%$ in wet ear and $92.3 \%$ in dry ear. ${ }^{17}$ Factors like age, sex, type of perforation were included in our study. Perhaps these factors do not have much influence on the outcome of graft uptake and post-operative hearing results. Thakur et al, in 2016, mentioned that there is no significant influence of age or gender on hearing outcome..$^{22}$ (Table V)

\section{Conclusion}

The present study shows statistically significant improvement in terms of graft uptake and hearing status post-operatively irrespective of the status of middle ear, whether dry or wet at the time of surgery. There is statistically no significant difference in terms of graft incorporation and hearing gain amongst these two groups. So we find no valid ground to postpone or cancel the tympanoplasty surgery in cases of central perforation when middle ear is wet and unnecessarily prolong the stress, anxiety and functional impairment of the individuals and further delay the waiting times for elective surgery. However a study with a larger sample size is needed to draw a firm conclusion.

\section{References}

1. Parmar SM, Sood A, Chakkal HS. Prevalence of chronic suppurative otitis media in school going children. Indian J Otol. 2018; 24:223-6

2. Saha AK. Otology \& Middle Ear Surgery. 1st ed: Jaypee, New Delhi;2016

3. Yaor MA, El-Kholey A, Jafari B. Surgical management of chronic suppurative otitis media; A 3 year experience. Annals of African Medicine 2006; 5(1):24-7

4. Worrall G. Common cold. Can Fam Physician. 2011; 57(11):1289-90

5. OECD. Health at a Glance 2015: OECD Indicators, OECD Publishing,Paris; 2015

6. Iacobucci G. NHS waiting times: number of patients waiting 18 weeks for treatment rises sharply. BMJ 2018; 361:k2114

7. Al- Juboori AN. Evaluation of spontaneous Healing of Traumatic Tympanic membrane. Gen Med. (Los Angel) 2014; 2:129
8. Glasscok ME, Gulya AJ. Eds Glasscock-Shambaugh: Surgery of the Ear: Tympanoplasty, 5th ed. Hamilton : BC Decker Inc, 2003

9. Patil K, Baisakhiya N, Deshmukh P T. Evaluation of different graft material in type1 tympanoplasty. Indian J Otol. 2014; 20:106-14

10. Lin YC, Wang WH, Weng HH, Lin YC. Predictors of surgical and hearing long-term results for inlay cartilage tympanoplasty. Arch Otolaryngol Head Neck Surg. 2011 Mar;137(3):215-9

11. Mishra P, Sonkhya N, Mathur N. Prospective study of 100 cases of underlay Tympanoplasty with superiorly based circumferential flap for subtotal perforation. Indian J Otolaryngol Head Neck Surg. 2007 Sept; 59(3) ; 225 -8

12. Nagle SK, Jagade MV, Gandhi SR, Pawar PV. Comparative study of outcome of type I Tympanoplasty in dry and wet ear. Indian J Otolaryngol Head Neck Surg. 2009; 61(2):138-40

13. Chandrasekhar Y, Chandrasekhar R. Comparison of efficacy of myringoplasty in dry and wet ears in chronic suppurative otitis media of tubotympanic type. International Journal of Otolaryngol Head Neck Surg. 2017 ; 3(3);705-9

14. Gamra OB, Nacef I, Ramdhane N, et. al. Tympanoplasty outcome in dry and wet ears. Otolaryngol Open J. 2016; 2(2) ; 51-7

15. Sivasankari L. A study of surgical outcomes of Tympanoplasties with or without cortical mastoidectomy. Ann Int Med. Dec. 2016; 2(5):EN-01-EN05

16. Pothala H, Shukla SC, Khan W, Ramalingam R, Ramalingam KK. A prospective comparative study between dry and wet tympanoplasty. AONO. 2018; 01(02):083-8

17. Hosny S, El-Anwar MW, Abd-Elhady M, Khazbak A, Feky AE. Outcomes of myringoplasty in wet and dry ears. Int Adv Otol. 2014; 10(3):256-9

18. Sheehy JL, Anderson RG. Myringoplasty. A review of 472 cases. Ann Otol Rhinol Laryngol. 1980; 89 (4pt 1):331-4

19. Anderson SA, Aabenhus K, Glad H, Sorensen MS. Graft takerates after tympanoplasty: results from a prospective ear surgery database. Otology \& Neurotology 2014; 35(10) ; e292-7

20. Shrestha S, Sinha BK. Hearing results after myringoplasty. Kathmandu University Medical Journal. 2006 ; 4(16), 455-9

21. Kumar G, Sharma R, Shakeel M, Jassal SS. Interlay myringoplasty: hearing gain and outcome in large central tympanic membrane perforation. Orissa J Otolaryngol \& Head and Neck Surgery 2016; 10(2):42-8

22. Thakur SK, Singh SK, Afaque A, Ghimire N. Outcome of Type I Tympanoplasty: An experience at Biratnagar Eye Hospital in Eastern Nepal. Asian Journal of Medical Sciences 2016; 7(2): $55-60$. 